\title{
Geração mapa temático para análise de problemas de Logística Urbana com uso da Geografia do Tempo e Sistemas de Informações Geográficas.
}

\author{
Heitor Anselmo Cruz*, Lilian da Silva Santos, Orlando Fontes Lima Jr.
}

\section{Resumo}

Esse projeto de pesquisa tem o intuito de analisar problemas relacionados à movimentação de carga na região central de Campinas sob a perspectiva das três restrições espaço-temporais (autoridade, capacidade e dependência) apresentadas por Torsten Hägerstrand em sua ciência intitulada Geografia do Tempo e com o auxílio de ferramentas de SIG.

\section{Palavras-chave:}

Geografia do Tempo e Sistema de Informações Geográficas, Geografia do Tempo e SIG, Geografia do Tempo e Análise Espacial.

\section{Introdução}

As cidades não são autossuficientes e necessitam de fluxos logísticos para sua manutenção. Esses fluxos estão acompanhados de problemas relacionados à Logística Urbana e que serão analisados sob a ótica da Geografia do Tempo. Para isso foram obtidas, por meio de pesquisas de campo, informações referentes a cada uma dessas restrições e que pudessem justificar a existência desses problemas, além de dados georreferenciáveis. A partir disso, com a utilização do ArcGIS, foi possível gerar mapas que contemplassem essa região e que estivessem associados a cada uma das restrições propostas nessa teoria, o que permitiu analisar a influência que cada uma dessas restrições exerce individualmente sobre as atividades vinculadas à movimentação de carga.

\section{Apresentação do Método}

O método utilizado foi dividido em três etapas.

A primeira consiste na delimitação da área de estudo.

A segunda consiste na definição das variáveis de acordo com a sua relação com as restrições analisadas.

A terceira consiste na investigação por meio de entrevistas com os responsáveis por estabelecimentos situados nessas áreas.

A última consiste na geração dos mapas temáticos.

\section{Resultados e Discussão}

É necessário apresentar e discutir as etapas do método de forma individual.

Inicialmente, foi definido o centro de Campinas/SP como a área de estudo. Tal definição se deu devido ao intenso fluxo logístico existente nessa região e às pesquisas já realizadas pelo Laboratório de Aprendizagem em Logística e Transportes (LALT).

Em seguida, escolheu-se as variáveis listadas e classificadas na Tabela 1.

Posteriomente, foram selecionados de modo randômico estabelecimentos que estivessem localizados na área de estudo e então foram realizadas entrevistas para obter dados referentes às variáveis estudadas.
Por último, foram gerados mapas temáticos com auxílio do ArcGIS para relacionar a área em estudo com os dados obtidos para as variáveis delimitadas, com o intuito de analisar individualmente a influência que cada restrição exerce sobre as atividades logísticas.

Tabela 1. Classificação da variáveis.

\begin{tabular}{|c|c|c|}
\hline Autoridade & Capacidade & Dependência \\
\hline Existência & área dos imóveis & Número de \\
de vagas de & Auncionários \\
carga e & & \\
descarga & & \\
\hline
\end{tabular}

\section{Conclusões}

Devido à predominância de publicações que abordam a Geografia do Tempo de forma unicamente teórica ou aplicada a movimentação de pessoas, é possível afirmar que esse projeto de pesquisa pode apresentar uma perspectiva diferente para a abordagem de problemas relacionados às atividades de movimentação de carga. Isso é consequência não só da aplicação dessa ciência, mas também da utilização de ferramentas computacionais que correspondem ao Sistema de Informações Geográficas.

\section{Agradecimentos}

Agradeço ao Programa Institucional de Bolsa de Iniciação Científica (PIBIC), ao CNPq, ao Laboratório de Aprendizagem em Logística e Transportes (LALT) e a Cassiano Gustavo Messias (doutorando da Geografia que colaborou com a elaboração dos mapas temáticos).

Agência Nacional de Transportes Terrestres (ANTT), 2006. Disponível <http://www.antt.gov.br/html/objects/_downloadblob.php?cod_blob=322>.

Acesso em: 28 abr. 2015

Arantes, T.G.F.; W.G, Ferreira (2011). O geoprocessamento na elaboração de mapas temáticos do transporte de cargas: Mesorregião do Triângulo Mineiro e Alto Paranaíba/MG. Geografia Ensino \& Pesquisa, v. 15.

Button, K.J. (2005) Can Freight Transport Models be Transferred across the Atlantic? In: Reggiani, A. and Schintler, L.A. (eds.) Methods and Models in Transport and Telecommunications. Springer, Berlin

Dias, M.L. e O.F. Lima Jr. (2014) Uso da abordagem de Living Lab no desenvolvimento de inovações em Logística Urbana. Anais do XXVIII Congresso da ANPET. Curitiba/PR 